\title{
Early Childhood Education and Relative Policies in China
}

\author{
Jiaxiong Zhu \\ East China Normal University \\ China
}

\begin{abstract}
This paper reviews the development of early childhood education in China in the recent 3 decades and examines the advantages and disadvantages of the relative policies made by the government. This paper mainly focuses on one child policy, the policies about early childhood curriculum reform and teacher education, and policies of early childhood education administration. Contemporary early childhood education is becoming more diverse in its forms, funding sources, and educational approaches, and is aligning itself with the increasingly open and diversified society. It is clear that early childhood education in China is strongly influenced by socio-cultural changes and conditions, and reflects the Chinese culture, the political system and influence of western cultures. Chinese early childhood educators and policy makers should re-think what has happened in the past years, especially the issues of cultural and regional appropriate, and continue to promote development in early childhood education.
\end{abstract}

Key words : Chinese early childhood education, relative policies, cultural and regional appropriate

Early childhood education in China plays an important role in Chinese society and in children's development. Contemporary early childhood education is becoming more diverse in its forms, funding sources, and educational approaches, and is aligning itself with the increasingly open and diversified society. It is clear that early childhood education in China is strongly influenced by socio-cultural changes and conditions and reflects the Chinese culture. Chinese early childhood educators and policy makers should re-think what has happened in the past years and continue to promote development in early childhood education.

Correspondence concerning this article should be addressed to Jiaxiong Zhu, Professor, Department of Early Childhood Education, East China Normal University, No. 3663, Zhongshan North Road, Shanghai, 200062, China. Electronic mail may be sent to Zhujx8@126.com

\section{The Current State of Early Childhood Education and Care in China}

Early childhood education in China refers to education for children from birth to age of 6 . There are mainly three types of early childhood education and care institutions in China. Nurseries are for children of 0-3 years old, kindergartens are for children of 3-6 years old, and the so-called "preschool classes" attached to primary schools are for 5-6 years old children (Zhu, J., 2002, December). Traditionally, the Ministration of Education is in charge of kindergartens and the Ministration of Hygiene is in charge of nurseries. Nowadays, kindergartens in some areas begin to enrol children of 2-3 years old, and also provide education and guidance service for 0-2 year old children and their families.

The Chinese government made policies by which 
early childhood education and care institutions might be run by multi-department, multi-unit and others in social sectors and with multi-funds. For example, The Regulations on Kindergarten Management and Rules on Kindergarten Routines were issues by the State Education Commission (the former Ministry of Education) in 1989, with approval of the State Council. Those two documents provide the legal basis for ensuring legal rights and interests of kindergartens, clarifying the responsibilities and obligations assumed by the governments, societies, and concerned departments, and also clarifying the administrative system with respect to responsibilities of local authorities and management at different levels (Zhu, M., 2006). The multi-sectors include education department, health department, family planning department, women's federation and so on, and form a cooperation system with responsibilities by individually concerned department.

In China, early childhood education is concerned as a part of basic education. The state and local education resources are generally scarce at the local and state level. The government pays attention on the 9-year compulsory education (6 years primary education and 3-year middle school education) when allocating education budget. Early childhood education is non-compulsory education. Chinese government only invested $1.3-1.4 \%$ of whole national education budget on early childhood education in the recent seventeen years. In 2007, there were 129.1 thousand kindergartens with 951.9 thousand staff members including teachers and directors. 77,616 kindergartens were private. The national enrolment of children in kindergarten was 23.49 million (Ministry of Education, P. R. of China, 2008). The enrolled rate of children aged 3 to 5 years in kindergarten was $44.6 \%, 55.6 \%$ was in cities and townships, and 35.6\% was in rural areas which account for about $70 \%$ of the total population.

Although great progress has been made in early childhood education in the past three decades, there are still many issues and problems facing educators and policy makers in China. There are many important policy and research issues, including, among others, the one child policy and early childhood education, the introduction of integrated birth-to-age 6 education and care, early childhood education in rural or remote areas, cultural changes and their effects on early childhood education, early childhood curriculum reform, teacher professional development and so on.

\section{The One Child Policy and Early Childhood Education}

China began implementing one child policy in 1979 with 6.1 million children getting singleton card. From 1970s to the end of last century, the number of newborn decreased 300-400 million since one child policy has been implemented. Now there are about 90 million singletons.

The one child policy has affected the world population, the economic development of China and so on in a greatly positive way. But it also might cause some problems. For example, many parents express their concerns that their only children are lonely and are missing out on valuable opportunities for social interaction (Tobin, Wu, \& Davidson, 1989). These concerns were reflected in the "4-2-1 syndrome" four dotting grandparents, two overindulgent parents, all investing their hopes and ambitions on "an emerging generation of spoiled, lazy, selfish, self-centered and overweight children".

Now, the singletons from 1979 are all reaching the marriage and child-bearing age. It's estimated that in next 10 years, the number of new families (which the singleton parents bring up singleton) will exceed 10 million. These parents play more and more important roles on social development of the next generation.

Actually there is no evidence indeed to demonstrate only children will get negative affirmation in their development till now. In fact, the early childhood educators, parents and others pay more attention on 
children's early education and development, not only on children's language, intelligence and health development but also on emotional and social development and education, including communication, friendship maintenance, emotional expressions, de-confliction, facing changes and new environment adaptation. In other words, only child policy has strengthened the emphasis on early education and the families' involvement and investment in their only child.

Family Planning Department is one of the official administrations and on behalf of carrying out the one child policy. Nowadays, this department partly transforms its work to early childhood care and education. That means the members of this department will go to the families and work with the parents about the care and education for the children from birth to 3 years.

\section{Early Childhood Curriculum Reform: From the 1980's to the Present}

In China, there have been three major eras of early childhood curriculum reform, in the 1920s-1930s, in the 1950s, and from the 1980s to the present time. From the 1980s, China started to carry out The Reform and Open-up policy, which greatly modified traditional education concepts and heavily effected on early childhood education. Many foreign theories, such as those of Dewey, Montessori, Bronfenbrenner, Bruner and especially Piaget and Vygotsky, began to spread widely in China, and the thoughts of recent modern Chinese educationists such as those of Xingzhi Tao, Heqing Chen and Xuemen Zhang were brought to the fore again. These ideas challenged the early childhood education rationale and practice that had existed for more than 30 years. The early childhood curriculum reform began with spontaneous experiments in different parts of the country, gradually expanding from a single subject to the whole curriculum, progressing from city to village, and actively propelling the early childhood curriculum reform on a large scale (Zhu, J., 2002, December).

The most influential measure of this reform was The Rules on Kindergarten Routines, issued by the National Education Committee in 1989. This document reflected the original aim of the reform; that is, that early childhood education should face the world, face the future and face modernization. Through administrative policies, the reform content was implemented to each level of administrative organizations and each kindergarten. According to this document, the spirit of the reform is mainly reflected in the following aspects: It emphasizes 1) child initiated activity, 2) individual differences, 3 ) the importance of play, 4) an integrated curriculum, and 5) the process of activities.

This document was immediately and widely disseminated throughout the country, and reform was implemented at all levels of administration and in all kindergartens. According to this document, early childhood curriculum should shift from an emphasis on teaching knowledge and skills to an emphasis on the development of children and the acquisition of abilities, from an emphasis on the result of educational activity to an emphasis on the process of activity, from an emphasis on the uniform curriculum standards to an emphasis on diversified and autonomous curriculum development and implementation.

This document adopted theories and practices from different cultures and presented progressive ideas and practices to early childhood educators in China. However, it has been difficult for practitioners to fully embrace this progressive ideology so long as powerful and deep-rooted cultural traditions run counter to modern scientific and democratic ideas (Wang \& Mao, 1996). There was a big gap between the rationale advocated by this document and educational practice. For example, the traditional values of obeying authorities and upholding unity are contrary to the goal of establishing a unique and democratic relationship between a teacher and each individual 
child. In addition, the lack of practical guidelines left many teachers not knowing how to implement the regulations. To solve these issues, the Ministry of Education (2001) issued The Guidance for Kindergarten Education (trial version). The Guidance takes into consideration the gap between progressive ideas and reality and offers compromise solutions by stating specific requirements and content in different domains.

The reform movement is still ongoing. Curriculum approaches are becoming more diverse and aligned with the increasingly open and diversified society. Different curricula such as the Project Approach, Reggio Emilia and Montessori have been widely adopted and localized (Li. H. \& Li, P., 2003). As a result, many new curricula have been developed. For example, the Integrated Theme-based Curriculum which is advocated by local government in Shanghai represents a localized progressive early childhood education approach (Zhu, J., 2002, September). Many kindergartens were required to develop their own school based curricula by the local administration department no matter they could do it or not.

The reform movement has been criticized by some scholars and educators. The critiques mainly focus on culturally appropriate of curriculum development.

\section{Culturally Appropriate of Curriculum Development}

This brief history of early childhood education in China reveals three distinct cultural threads traditional culture, communist culture, and Western culture, which have combined to profoundly shape Chinese people's lives and also different aspects of Chinese early childhood education (Wang \& Spodek, 2000). Thus, the contemporary early childhood curriculum in China can be seen as reflecting a hybrid of these three cultural threads (Zhu \& Wang, 2005). The curriculum development and reform have to concern all of these three cultural threads and make them balance.

Traditional Chinese culture has greatly influenced Asian countries from ancient times. Chinese people are more group-oriented, or social unit-oriented as opposed to individual-oriented, and more extrinsically motivated as opposed to intrinsically motivated. People also tend to value drilling, memorizing and discipline rather than creativity, understanding and freedom (Chan, 1996; Cheng, 1996). Confucianism has greatly influenced Chinese educational ideas. In the context of globalization, it may be good for Chinese people to modify their traditional culture, but not to change their own culture totally. Actually it is impossible to change their own culture totally. As Tobin, Yeh and Karasawa (2006) argued, preschools are institutions that both reflect and support the cultures of which they are a part. In this sense, preschools are inherently conservative institutions, institutions mandated to produce the kind of child the culture most values.

Mascolo (2008) did his comparison work about Chinese culture and American culture, and pointed out the differences of the school programs between these two cultures.

The influence of this hybrid on early childhood education has been selective, dynamic, and changing. First, each of the three cultural threads has shaped different aspects of early childhood education. While the influence of the communist culture is evident in practical aspects of kindergarten education, such as organization, administration, and curricular goals and content, traditional culture has had a profound influence on the ideological and philosophical bases of kindergarten, including views of the young child, views of learning and development, and views of appropriate teacher-child relationships.

Sometimes one cultural thread counteracted another. For example, individuality is one of the main goals of the new EC curriculum. It emphasizes individual differences, individual needs, individual choices, individual expression and etc. But this might pose a threat to the communist social order. McClelland (McClelland, 1961) has pointed out that the achievement-oriented ego style that is a prerequisite of economic development tends to 
Table 1.

Cultural Foundations of School Program in United States and China

\begin{tabular}{|c|c|c|}
\hline & American Individualism & Chinese Confucianism \\
\hline Culture & $\begin{array}{l}\text { Individual Freedom, Equality and Choice } \\
\text { - Morality: Individual Rights and } \\
\text { Responsibilities } \\
\text { - Moral Domain Separate from Social } \\
\text { Convention } \\
\text { - Equality: Individuals are Equal; Equal } \\
\text { - Opportunity } \\
\text { Personal Freedom: Free to Choose Own } \\
\text { - American Dream: Individuals Make their } \\
\text { Own Destinies }\end{array}$ & $\begin{array}{l}\text { Social Honor and Harmony within Moral Hierarchy } \\
\text { - Honor: Familial Honor; Awareness of } \\
\text { Evaluations of Others } \\
\text { - Harmony: Modesty, Respect; Acknowledge Others } \\
\text { - Moral Hierarchy: Filial Piety; Obedience and } \\
\text { Care; Shame } \\
\text { - Self-Cultivation: Learning and Self-Perfection for } \\
\text { Family Honor as Moral Value }\end{array}$ \\
\hline School & $\begin{array}{l}\text { Child-Centered Education } \\
\text { - Student Focused: Teacher Adjusts to Student } \\
\text { Abilities } \\
\text { - Localized Control: Courses, Textbooks, Exams } \\
\text { - Value on Education: Lower Expectations; } \\
\text { Mixed Parent Involvement } \\
\text { - Duration: Shorter/Fewer Days; } \\
\text { Extracurricular Activities seen as Important; } \\
\text { Less Homework } \\
\text { - Self-as-Learner: Intelligence and Ability as } \\
\text { Fixed } \\
\text { - Process Focus: Teaching Process; Learning } \\
\text { Styles } \\
\text { - Many Behavior Problems/Lower } \\
\text { Achievement Anxiety }\end{array}$ & $\begin{array}{l}\text { Traditional Teacher-Centered Education } \\
\text { - Teacher Focused: Teacher Sets Rigorous } \\
\text { Academic Agenda } \\
\text { - Nationalized Standards: Courses, Textbooks, } \\
\text { Exams } \\
\text { - Value on Education: High Standards; Extreme } \\
\text { Parent Involvement } \\
\text { - Duration: Longer Days; More School Days; Extra } \\
\text { Tutorials; More Homework; Fewer Extracurricular } \\
\text { - Activities } \\
\text { - Self-as-Learner: Intelligence as Malleable; Growth } \\
\text { Mindset } \\
\text { - Fontent Focus: Deep Content and Rote } \\
\text { Knowledge } \\
\text { Anxiety }\end{array}$ \\
\hline
\end{tabular}

Note. From "Pathways in the cultivation of the learning motivation in young children: Culture and the emotional foundations of learning" by M. F. Mascolo, 2008, Presentation at the second cito conference on early childhood education on March 7, 2008, the Netherlands.

encourage selfishness and thus to pose a threat to social cohesion if it is not corrected by an emphasis on "other directedness" and "collectivist" in the education system.

The pattern of influence has changed over time. In the post-Mao era (1976-), European-American culture has emerged as an important cultural source and has exerted an increasingly powerful influence. The progressive ideology regarding children, educational values, and the curriculum has been a strong force in early childhood education reform in recent years. Meanwhile, the communist culture's control and the 
influence of traditional culture on early childhood education have been waning ideologically and philosophically (Li, H., 2007). But there have been no major practical changes, especially in most developing areas.

In recent years, many curriculum and pedagogical models have been introduced to China. These include the Montessori curriculum, the Project Approach, High/Scope, Reggio Emilia, Developmental Appropriate Practice (DAP) and the Whole Language Approach. Many kindergarten directors and teachers have tried to imitate or adapt these models, but some of them have failed (Li, H. \& Li, P., 2003).

Following recent research in China, Tobin (2007) concluded that the government was using the reform of early childhood education as a tool for producing a labour force able to compete more effectively in the global economy:

Many American early childhood educators would no doubt welcome the spread of constructivism, learning centres, self-expression, and the project approach in Chinese preschools. But as an educational anthropologist I worry about how these approaches will be integrated with Chinese cultural values and be made responsive to the concerns and conditions of local Chinese communities. Many countries in Africa, Latin America, and Asia that are much poorer than Turkey and China have much less ability to stand up to pressure to introduce a Western approach to early childhood education. Help from North Americans in developing their systems of early childhood education is welcomed by many poor countries, but it is important that they do so on their own terms, in ways that respect their local cultures. (p.142)

Actually there is no high quality curriculum that can be effectively adopted in all different cultures. It is important for us to look into and think about the culturally embedded nature of these successful curricula and identify these cultural factors in the process of appropriating and localizing any borrowed curriculum. Just as Tobin (2007, p. 143) said, "Cultural traditions of childcare and education should be respected and valued (which isn't to say that they should not also be critiqued and changed) and differences across nations and cultures in approaches to early childhood education should be respected and not treated as deficits. To do otherwise is to engage in colonialism, ethnocentrism, and intellectual provincialism".

\section{Re-thinking the Early Childhood Curriculum Reform}

In China, reform of the economic, social and political systems has made great progress and is still ongoing. The reform and open-up policy has brought significant advances in the past 30 years but new problems crop up when old ones get solved. We never expected that the levels of one-parent families, child abuse, sexual discrimination and ethnic diversity would increase so quickly.

The main goal of reform now in China is to establish a "harmonious society". Development economically, culturally, educationally, medically and so on is very unbalanced throughout the country, as are developments in early childhood education. Realizing educational equity is concerned as one of the most important things. One of the basic challenges face early childhood education is to improve the enrolment rate of children aged 3 to 6 years, especially in the rural areas since an acute imbalance exists between urban and rural areas. Another basic challenge is how to deal with the early childhood left-behind children whose parents have moved from rural area to the cities.

To deal with these problems, the government changed the management system of basic education. For example, in 2001, the State Council clarified that the management was to be change from the township level into mainly country level. This meant the individual county-level governments took more responsibilities for the basic education. This change brought new opportunities for the development of early childhood education. The Chinese government issued The Guidelines of Child Development for 2001 though 2010 in order to creating the opportunity for 
receiving good early childcare and education for each child (Zhu, M., 2006).

To deal with these problems, we need to rethink of the early childhood curriculum reform. Early childhood curriculum reform in China, especially in the rural area should be sensitive to social ecology and regional culture. The early childhood curriculum reform in many areas should not depend too much on European-American ideas and should not pay too much attention to a single quality standard. China is a big country and there are obvious differences between eastern and western, rich and poor, and urban and rural areas. We need to focus on all groups in different areas and create equitable social, cultural, economic, and political relationships among them. Early childhood curriculum reform in China should acknowledge these differences between different groups in different areas and develop different curricula for them (Zhu, J., 2004).

\section{Early Childhood Teacher Education}

Teacher education is an endeavour aimed at future. The future orientation in early childhood teacher education in China has a dove-tailed perspective: On the one hand, the teacher education programs must adapt to the rapid economic development, meet the demands for educating citizens who will be capable, innovative and worldly. On the other hand, early childhood teacher education in China should be in line with the Chinese culture and national conditions to create a "harmonious society" under the principles of justice and equality.

In a few developed areas, kindergartens teachers are equivalent to the elementary and secondary school teachers in social and economical status. But the nature of non-compulsory education for young children in many areas places, especially in the rural areas teachers in a low social and economical status. The preserve teacher education and in-service training present many problems. For example, regarding kindergartens in China, there are 721,609 full time kindergarten teachers, 114,511 directors, making a total of 836,120. Among these teachers and directors, 51,219 people or $6.13 \%$ have bachelor degree and 359,773 people or $43.02 \%$ had 2 or 3-year college education. And yet, more than one half of these teachers and directors have no professional trainings. (Ministry of Education, P. R. of China, 2005)

For four decades after 1950, Chinese kindergarten teachers had been trained mainly in the normal school, a vocational school that admitted graduates from the junior middle school. These students would study for three more years to become kindergarten teachers. In the recent decade, the older Chinese system of kindergarten teacher education has been transformed to a system from 3 tiers (vocational normal school, junior college, and 4-year college) to 2 tiers (junior college and 4-year college). But this transformation is not uniform change. Some normal schools have become 3-year vocational colleges while others have been incorporated into nearby teachers colleges or normal universities that offer bachelor degrees. In addition to the formal education, state and local governments also provide education for pre-service and in-service teachers through distance education, self-teaching, and internet education programs. As a result, a large number of teachers have had three or more years of college education. In some well-to-do regions, almost all kindergarten teachers have such a diploma or degree.

Since the late 1980's, the Chinese government has promoted the curriculum reform throughout the country. Early childhood curriculum has shifted from an emphasis on the uniform curriculum standards to an emphasis on diversified and autonomous curriculum development and implementation. The curriculum reform has indeed challenged the traditional paradigm of teacher education and has frequently and strongly called for a paradigm shift. A host of national and local policies, laws and regulations, demand that early curriculum should be the centre of all activities in kindergartens. It requires early educators to examine children's experiences, interests and needs, engaging children in the activities 
that teachers and children collaboratively initiate and select to carry out. Teachers play a central role in the curriculum reform which requires them to study the educational processes and the experiences of children. To implement a new curriculum, teachers must perform at a much higher level than executing a standardized curriculum because the new curriculum places teachers in a decision-making position in both curriculum design and implementation.

But the majority of early childhood teachers were accustomed to the curriculum and way of teaching which were adapted from the USSR (from 1950 to the 1980s) and did not deeply understand the essence of child-oriented educational theory or the practical application of child-oriented activities. In the process of the curriculum reform, early childhood teachers know more new theories and ideas about education and teaching, but such knowledge does not automatically bring changes in educational practices. When teachers face complicated and varied pedagogical contexts, it can be very difficult to make sure that their teaching is meaningful. Anecdotal evidence suggests that some early childhood teachers even complain that teachers who could teach well in the past now don't know how to teach, while the teachers who didn't know how to teach in the past have now become more happy-go-lucky.

The government tried to push a movement to promote teacher's professional development. Authorities of officers and scholars advocated that teacher should be researcher. That means teachers should attend school based research and reflect their own classroom behaviours, and make authentic connections between the learning tasks they plan, and the activities which children themselves initiate. Teacher need not only to reflect on past and on-going behaviours, but also on the process of reflection.

However, it is really difficult for the most of teachers to do that practically even though they almost spend all of their energy. Some teachers complain and some teachers just do whatever they want to do.
The transformation and improvement of early childhood teacher education in China is an ongoing process. Developing an effective mechanism for early childhood teacher education, this could support diverse, flexible and context-sensitive practice. Organizations for pre-service and in-service professional development at different government levels have been established as needed. Formal and informal educations for teachers have been made available. Early childhood teacher education programs in China have widely taken the various types of measures and strategies. For examples, some programs have been designed for high-level teachers and promote their engagement in critically reflective activities that help to shape innovative and supportive environments, and some have been designed for majority of teachers and make them easy to master in the classroom situation. In comparison with urban areas, teacher education in rural areas is in desperate needs of more resources and professional development opportunities are scanty. In order to alleviate this situation, some rural governments already set aside funds to purchase distance education service and other means for providing professional development.

\section{Developing Integrated Birth-to-6 Care and Education}

In recent years, there has been an increasing effort to integrate nurseries and kindergartens and form continuous care and education for children from birth to age 6. With the increasing consensus on the importance of education for infants and toddlers, the educational administration is gradually taking over responsibility for managing nurseries. The state advocates the establishment of a development index system to help parents and caregivers to "improve scientific care and education for young children" (Zhu, J., 2002, December). More and more kindergartens have begun to enrol children as young 
as two- or three-years-old. Some kindergartens even help nurseries to improve their educational services to young children and their families.

To achieve unified provision of care and education for children from birth to 6, some local governments established an ambitious goal for a system which is planned as a whole by government leaders, administered by state educational departments, and coordinated by other related departments; and which relies on the community and involves parents and various educational institutes.

However, there are many barriers to these integration efforts. Two main issues are the separate administration and the lack of resources.

\section{References}

Chan, J. (1996). Chinese intelligence. In M. H. Bond (Ed.), The handbook of Chinese psychology (pp.93-108). Hong Kong: Oxford University Press.

Cheng, K. M. (1996). The quality of primary education: A case study of Zhejiang Province, China. Paris: International Institute for Educational Planning.

Li, H. (2007). Universalism versus relativism: Cultural reflections on the ECE reforms in China. Shanghai: East China Normal University.

Li, H., \& Li, P. (2003). Lessons from implanting Reggio Emilia and Montessori curriculum in China (in Chinese). Preschool Education, 9, 4-5.

Liu, Q. (2003). Understanding difference culture patterns or orientations between East and West. Investigations Linguistic, 9, 21-30.

Mascolo, M. F. (2008, March). Pathways in the cultivation of the learning motivation in young children: Culture and the emotional foundations of learning. Presentation at the second cito conference on early childhood education, Arnhem, Netherlands.

McClelland, D. (1961). The achieving society. Princeton, NJ: Van Nostrand.

Ministry of Education, P. R. of China. (2001). The guidance for kindergarten education (trial version). Retrieved June 5, 2008, from http://www.moe.edu.cn/edoas/website18/92/i nfo692.htm

Ministry of Education, P. R. of China. (2005). China education yearbook 2005. Beijing, China: People Education Press.

Ministry of Education, P. R. of China. (2008). 2007 report for national education development, China Education Daily, May 5, 2008.

Tobin, J. (2007). An ethnographic perspective on quality in early childhood education. In J. Zhu (Ed.), Global perspectives on early childhood education (pp. 131-143). Shanghai: East China Normal University Press.

Tobin, J., Wu, D., \& Davidson, D. (1989). Preschool in three cultures: Japan, China, and the United States. New Haven, CT: Yale University Press.

Tobin, J., Yeh, H., \& Karasawa, M. (2006). Continuity and change in preschool in three cultures. In M. Takeuchi (Ed.), New directions for early childhood education and care in the $21^{\text {st }}$ century: International perspectives (pp. 184-215). Waverly, IA: G \& R Publishing Co.

Wang, J., \& Mao, S. (1996). Culture and the kindergarten curriculum in the People's Republic of China. Early Child Development and Care, 123, 143-156.

Wang, X. C., \& Spodek, B. (2000, November). Early childhood education in China: A hybrid of traditional, communist, and western culture. Paper presented at the annual meeting of the National Association for the Education of Young Children. Atlanta, GA.

Zhu, J. (2002, December). Early childhood care and education in P. R. of China. Paper presented at 2002 KEDI-UNESCO Bangkok Joint Seminar and Study Tour on Early Childhood Care and Education. Seoul, Korea.

Zhu, J. (2002, September). Early childhood curriculum reform in Shanghai kindergartens: Case studies. Keynote address at the OMEP/ICEC Asia Pacific 
Early Childhood Conference, Singapore.

Zhu, J. (2004). Reflection on the two-decade reform in early childhood curriculum in Mainland China. Hong Kong Journal of Early Childhood, 3(2), 5-8.

Zhu, J., \& Wang, X. C. (2005). Early childhood education and research in China. In B. Spodek, \& O. Saracho (Eds.), International perspectives on research in early childhood education contemporary (pp.55-77). Charlotte, NC: Information Age Publishing.
Zhu, M. (2006). The development and reform of early childhood education in China: Practices and explorations in multi-sectoral cooperation in administrative systems. In M. Takeuchi (Ed.), New directions for early childhood education and care in the $21^{\text {st }}$ century: International perspectives (pp. 33-65). Waverly, IA: G \& R Publishing Co. 